Revue musicale OICRM

\title{
Présentation des Notes de terrain
}

Federico Lazzaro

Volume 4, numéro 2, 2017

URI : https://id.erudit.org/iderudit/1043225ar

DOI : https://doi.org/10.7202/1043225ar

Aller au sommaire du numéro

Éditeur(s)

Observatoire interdisciplinaire de création et recherche en musique (OICRM)

ISSN

2368-7061 (numérique)

Découvrir la revue

Citer ce document

Lazzaro, F. (2017). Présentation des Notes de terrain. Revue musicale OICRM, 4(2), 162-162. https://doi.org/10.7202/1043225ar d'utilisation que vous pouvez consulter en ligne.

https://apropos.erudit.org/fr/usagers/politique-dutilisation/ 


\title{
Présentation des Notes de terrain
}

\author{
Federico Lazzaro
}

À partir de ce numéro, la Revue musicale oICRM hébergera dans ses " Notes de terrain » une série d'études en lien avec le projet de recherche «Histoire de l'esthétique musicale en France, 1900-1950 (PHEM), dirigé par Michel Duchesneau et coordonné par Federico Lazzaro au sein de l'équipe «Musique en France aux XIX et Xx discours et idéologies » (ÉMF). Dans le présent numéro, un article de Federico Lazzaro présente le cadre théorique et méthodologique du projet, suivi par deux cas d'étude : Michel Duchesneau analyse le discours esthétique du critique Raymond Bouyer ; Judy-Ann Desrosiers et Federico Lazzaro offrent un aperçu, sous la forme d'anthologie commentée, de l'utilisation des concepts d'internationalisme et de cosmopolitisme par les musicographes français de la première moitié du $\mathrm{xx}^{\mathrm{e}}$ siècle. 